\title{
Host-Parasitoid Relationship: Pachycrepoideus vindemmiae (Rondani) (Hymenoptera: Pteromalidae) collected in Zaprionus indianus Gupta (Diptera: Drosophilidae) in Brazil
}

Carlos Henrique Marchiori ${ }^{1}$

1 Instituto Federal Goiano

Study presented at the Biological Control Symposium.

The genus Zaprionus is compounded by 56 species, and Zaprionus indianus Gupta (Diptera: Drosophilidae) seems to be the only species spreading out around the globe, mainly due to the international fruit trading. This Drosophilidae is probably from Africa, where it was registered in fruits of 74 plant species.(Vilela et al., 1999; Vilela et al., 2001).

Pachycrepoideus vindemmiae (Rondani) (Diptera: Pteromalidae) is a solitary parasitoid of numerous Diptera from families Anthomyiidae, Calliphoridae, Muscidae, Tachinidae, Tephritidae and others (Hanson \& Gauld, 1995)

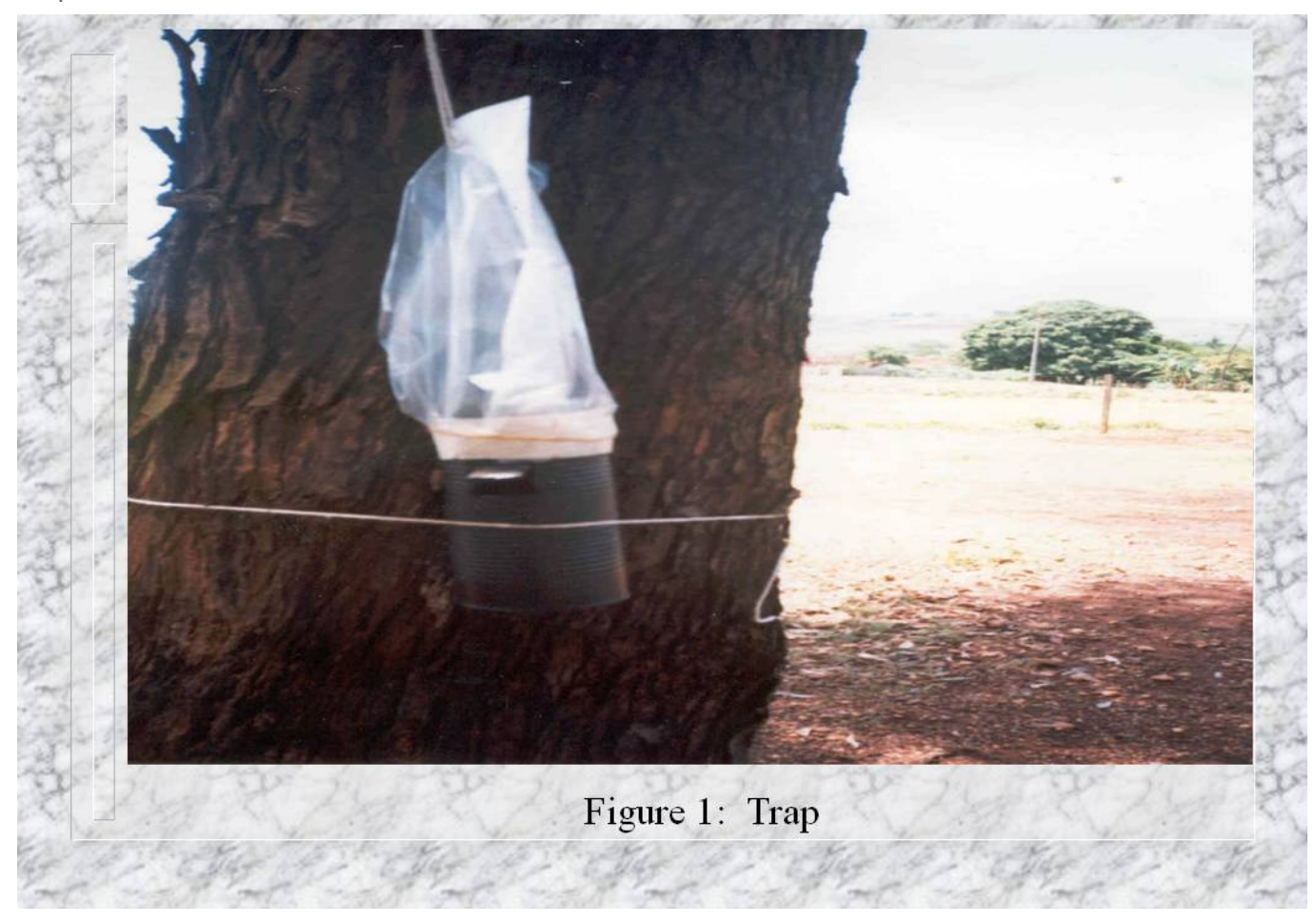


Objective: To report the host-parasitoid relationship.

Dipterous were attracted to traps made of dull black tin foil cans, measuring $19 \mathrm{~cm}$ in height and $9 \mathrm{~cm}$ in diameter, with two venetian blind type openings placed in the inferior third to allow insects entering. To the upper part of the cans, nylon funnels with opened extremities and bases turned down, were attached. These traps were then wrapped with plastic bags, which after removal would allow the capture of dipterous and parasitoids (Figure 1). Fruits (pear, apple and banana) deposited on the ground were used as baits inside the cans. Five of these traps were suspended on Eucalyptus sp. trees at $1 \mathrm{~m}$ above the soil level, $2 \mathrm{~m}$ apart from each other and $50 \mathrm{~m}$ away from a domestic garbage deposit. The specimens collected were taken to the laboratory, killed with ethyl ether and preserved in $70 \%$ ethanol for further identification. After retrieval of insects, the traps contents were placed into plastic containers containing a layer of sand to serve as substrate for larvae population. After remaining 15 days in the field the sand of these containers was sifted for extraction of pupae obtained in a natural environment. These pupae were then individually transferred to gelatin capsules (number 00) to obtain dipterous and/or parasitoid.

During the study, 963 Z. indianus (Figures 2 and 3) pupae were obtained, of which were collected 285 specimens of $P$. vindemmiae (Figure 4), with a percentage of parasitism of $29.5 \%$.

The nature of this relation, however, has to be deeper studied in order to permit a better evaluation of the impact of these parasitoids on the insect pest population. Since these parasitoids are natural enemies of insect pests, the feasibility of their use as biological control agents on the fig is an encouraging possibility.

\section{REFERENCES}

Hanson, P.E. \& Gauld, I.D. The Hymenoptera of Costa Rica. Oxford: Oxford Univ. Press, 1995. 893p.

Vilela, C.R., Teixeira, E.P., Stein, C.P. Nova praga nos figos: Zaprionus indianus Gupta, 1970. Info. Soc. Entomol. Bras., v.4, n.2, p.1-5. 1999.

Vilela, C.R., Teixeira, E.P., Stein, C.P. Mosca-africana-do figo, Zaprionus indianus (Diptera: Drosophilidae). In: Vilela, E.F., Zucchi, R.A., Cantor, F. (Eds). Pragas introduzidas no Brasil. 
Ribeirão Preto: Holos, 2001. p.48-52.
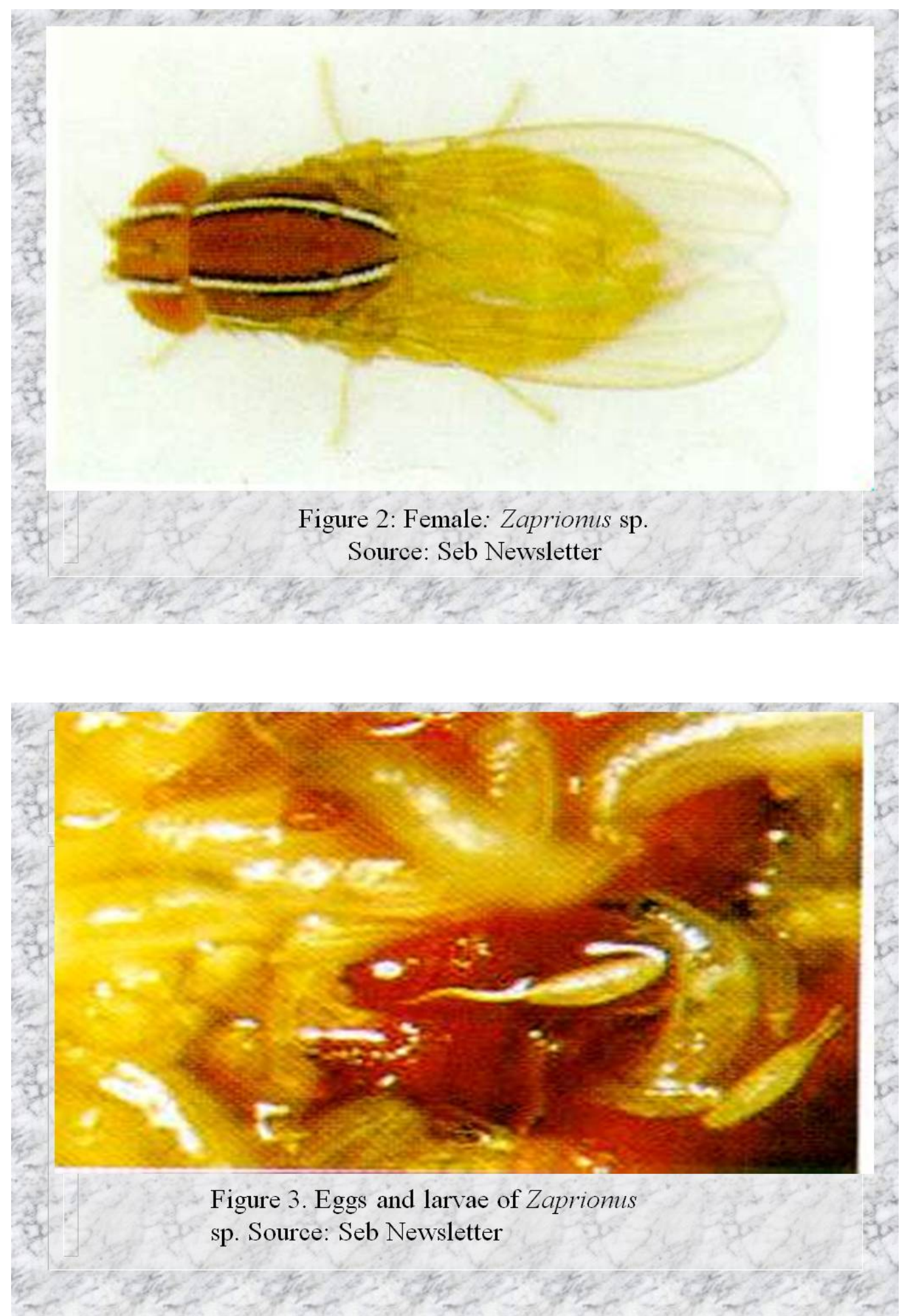


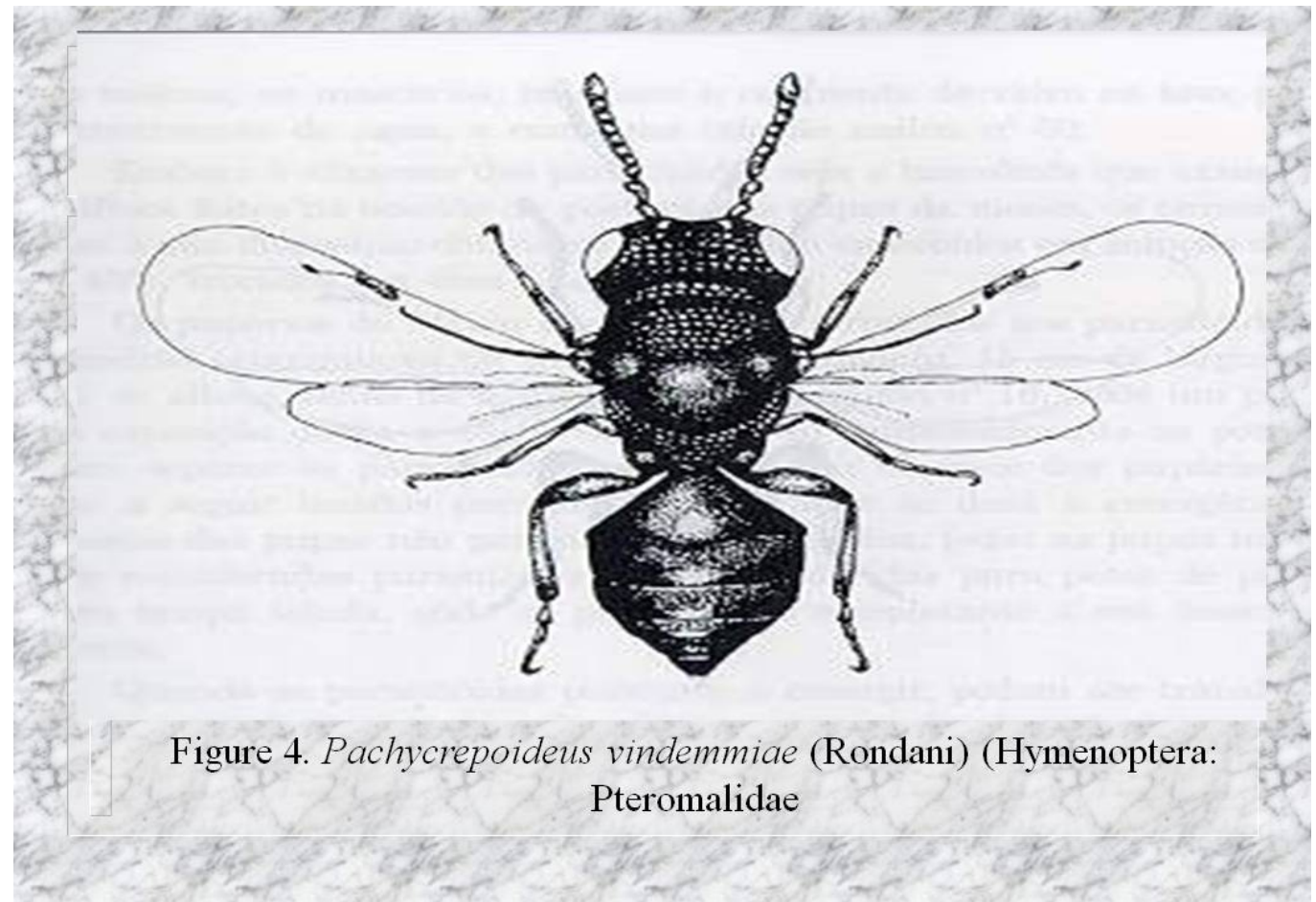

